\title{
Helpful family climate moderates the relationship between perceived family support of ADHD symptoms and depression: a conditional process model
}

Pichaya Pojanapotha², Chiraphat Boonnag ${ }^{1}$, Sirinut Siritikul', Sirikorn Chalanunt ${ }^{1}$, Pimolpun Kuntawong ${ }^{2}$, Nahathai Wongpakaran ${ }^{2}$ and Tinakon Wongpakaran ${ }^{2^{*}}$ (D)

\begin{abstract}
Background: Symptoms of attention deficit hyperactivity disorder (ADHD) are commonly comorbid with depression This study aimed to examine the relationship between ADHD symptoms and depression through perceived family support and to explore whether the magnitude of the relationship depended on the type of family climate of medical students.

Methods: This cross-sectional study was conducted among 124 first year medical students in Thailand. Participants completed questionnaires on ADHD symptoms, depression, perceived family support, and 9 types of family climate. The questionnaires included the Adult ADHD Self-Report Scale Screener, Patient Health Questionnaire-9, and revised Thai Multidimensional Scale of Perceived Social Support. Mediational analysis was adopted to examine the mediating role of perceived family support in the relationship between ADHD symptoms and depression, while moderation analysis was applied to examine the extent of the relationship depending on family climate.

Results: The relationship between ADHD symptoms and depression was moderate. Perceived family support partially mediated this relationship after controlling for age and sex. Among the types of family climate, only helpful family climate was a significant moderator of perceived family support and depression. The moderated mediation model increased the variance in depression from $17 \%$ by the mediation model to $21 \%$. However, follow-up conditional mediational analysis showed that the indirect effect of ADHD symptoms on depression via perceived family support was not significant and that this effect did not vary linearly as a function of helpful family climate.

Conclusion: The findings of the study revealed that poor family support might be one risk of developing depression in the context of ADHD symptoms. Further study on providing intervention concerning family support among those with ADHD symptoms should be warranted. In addition, a study on helpful family climate in a larger sample size, in other populations, and in a longitudinal fashion for a more robust conclusion is encouraged.
\end{abstract}

Keywords: Adult ADHD, Undergraduate, Family support, Depression, Family climate

*Correspondence: tinakon.w@cmu.ac.th

${ }^{2}$ Department of Psychiatry, Faculty of Medicine, Chiang Mai University, 110 Intawaroros Rd., T. Sriphum, A. Muang, Chiang Mai 50200, Thailand Full list of author information is available at the end of the article

\section{Background}

Attention-deficit/hyperactivity disorder (ADHD) is a neurodevelopmental disorder that affects many areas of life from childhood to adulthood [1, 2]. ADHD symptoms include impairment in executive functions, such as 
self-regulation, time management, organization, working memory, planning, and cognitive flexibility, which are usually followed by academic failure, undermined work performance, and social problems [3-5]. On the whole, it leads to poor self-esteem and depression [6, 7].

ADHD is rarely acknowledged among adults, especially those who have never been treated as children [8]. A study has shown that $5.5 \%$ of adults reported received a diagnosed of ADHD, and most (72\%) had the diagnosis after the age of 18 [9]. ADHD symptoms can affect learning and work efficiency and decrease the likelihood of achievement and happiness in many aspects of life [10$12]$, including quality of life $[13,14]$.

ADHD is commonly comorbid with depression. According to Pehlivanidis, psychiatric disorders, especially depressive disorders, are highly prevalent comorbidities of newly diagnosed adult ADHD [15]. The prevalence of depression in ADHD ranges from 18.6 to $53.3 \%[1,16-18]$. A longitudinal study showed that $17 \%$ of adults with a diagnosis of ADHD had depression as a comorbidity [19]. In addition to depression, among young adults, e.g., medical students, ADHD symptoms were also found to be significantly associated with alcohol consumption and suicidal behavior [20-22]. The mechanism of developing depression in ADHD is not fully understood; it may be attributed to various factors. Some studies have shown associations with self-esteem, perceived social support, and family climate [6, 23-26].

The treatment for ADHD includes both pharmacologic and psychosocial aspects. Family climate is one of the most important psychosocial factors associated with behavioral outcomes or symptoms. No systematic methods can describe and measure family climate. The ideal family climate is warm and stable, as this may help support children when they encounter challenges in life [27]. Some have described it using terms such as 'democratic', 'authoritarian,' 'extra-protection' and 'neglect', while some use broader terms such as 'favorable' [28] or 'aversive' emotional climate [29]. To be able to classify family climate as positive or negative would be useful for clinical applications. Related work has shown that negative family climate is associated with externalizing behavior [30]. Both family issues and development of ADHD symptoms can have a bidirectional effect; for example, child impulsivity or activation can trigger parental hostility, which may lead to continuation of ADHD in the child [31-33]. A less favorable family climate is associated with ADHD symptoms [28]. Nevertheless, while most studies have analyzed the relationship between negative family environment and ADHD symptoms, positive environmental factors have often been ignored.

Perception of the family climate is our subject of interest because it affects an individual's emotions, thinking, and behavior, regardless of what the real family climate is [30]. The ideal family climate should be warm and stable, as it may help support the child when they encounter challenges in life [27]. However, no systematic methods exist to describe and measure family climate. Studies investigating positive climate have illustrated it by family cohesion and communication [34] and warmth, supportiveness, and interpersonal engagement of the family [35], while those investigating negative family climate demonstrated it by undesirable family environments, emotionally unstable parents [36], authoritative parenting styles [37], highly emotional expressions and overinvolvement [30], and lack of emotional support, irritability, and intrusiveness [38]. Family climate is an essential predictor of youth depression [39], particularly negative family climate [40].

Based on the findings of these studies, ADHD symptoms, perceived family support, and family climate have an influence on depression among young adults. The effect is not only direct; an indirect effect of ADHD symptoms on depression via many factors has also been found. These mediators include the parent-child relationship, parenting stress, lack of social support, exposure to community violence, peer problems, and victimization [41-45]. However, indirect effects of ADHD symptoms on depression mediated by perceived family support and family climate have never been reported.

This study aimed to examine the relationship between ADHD symptoms and depression through perceived family support and to investigate whether the magnitude and direction of the relationship depended on family climate. Based on the findings of previous studies, we hypothesized that ADHD symptoms would positively relate to depression, while poor perception of family support would be more likely to be associated with increased depression. Positive family climate should be negatively associated with depression while negative family climate should be positively associated with depression.

\section{Methods}

\section{Study population and procedure}

This study surveyed 124 participants who were first year medical students at Chiang Mai University, Thailand. The sample was recruited in 2017 using convenience sampling. Each participant gave written informed consent before completing the questionnaires, which included sociodemographic data and information relating to the parental and family environment, the Adult ADHD SelfReport Scale (ASRS) screener, perceived family support questionnaire, and depressive symptom questionnaire. Ethics approval was obtained from the Faculty of Medicine, Chiang Mai University, Thailand, before taking any further steps in the research. 


\section{Instruments}

\section{General demographic data}

The self-reported questionnaires consisted of items on sociodemographic and health-related characteristics, including sex, age, underlying diseases, and family income. They also included nine factors that characterized family climate as perceived by the participant: quietlonesome, vivacious, chaotic, ignoring/detached, helpful, intrusive, warm-relaxing, distant, and uncomfortable/ tense. In addition, information was collected on the parents' education, occupation, and history of underlying physical and mental illness.

\section{Adult ADHD Self-Report Scale (ASRS) screener V1.1}

ASRS, developed by Kessler et al., is a six-item self-rated questionnaire measuring ADHD symptoms, and includes four items measuring inattention (items 1-4), and two items measuring hyperactivity (items 5-6) [46]. These six items are (1) trouble wrapping up the final details of a project, (2) difficulty getting things in order, (3) problems remembering appointments or obligations, (4) avoiding or delaying getting started, (5) fidgeting or squirming with hands or feet when sitting for long, and (6) feeling overly active and compelled to do things. The responses range from 0 to 4 (never to very often). Subjects reporting higher total score, present higher levels of ADHD symptoms. An individual with at least four symptoms is classified as having ADHD. The Thai version of the ASRS-v1.1 screener has been validated and used for screening adult ADHD; it shows a sensitivity of 0.93 and a specificity of $0.71[47,48]$. Cronbach's alpha for the study sample was 0.80 .

\section{Patient health questionnaire (PHQ)-9}

The PHQ-9 is a nine-item self-reporting questionnaire measuring the extent to which an individual has experienced depressive symptoms over the past two weeks [49]. The four-response Likert scale ranges from 0 (not at all) to 3 (nearly every day). Subjects reporting higher total score, present higher levels of depressive symptoms. Cronbach's alpha for the Thai version of the PHQ-9 is 0.79 , and a positive association was noted between the PHQ-9 and the Hamilton Rating Scale for depression $(r=0.56, p<0.001)$ [50]. Cronbach's alpha for the study sample was 0.85 .

\section{Revised-Multidimensional Scale of Perceived Social Support (rMSPSS)}

The rMSPSS tool measures the extent to which an individual has experienced support by significant others (SO), friends (FR), and family (FA) [51]. It comprises 12 questions, with responses rated on a seven-point
Likert scale ranging from very strongly disagree (0) to very strongly agree (6). Subjects receiving higher scores, present higher levels of perceived social support. The revised Thai version demonstrated good psychometric properties [52]. In this study, only the family subscale was used; its Cronbach's alpha was 0.88 .

\section{Statistical analysis}

Descriptive statistics-frequency, percentage, and mean and standard deviation-were obtained for sociodemographic, ADHD-symptom and mental health-related data. Mean and standard deviation were calculated for continuous data. In the case of discrete data, such as sex, the amount and percentage were obtained. Between group differences and correlations were analyzed using independent $t$-tests and Pearson's correlation.

In the analysis of the mediation and moderation models, we began by examining the magnitude of the relationships between ADHD symptoms, depression, perceived family support, and family climate using zeroorder correlations. For mediation analysis, we used the methods discussed by Hayes [53] to examine the relationship between ADHD symptoms and depression through perceived family support (Fig. 1). For moderation analysis, we conducted tests to determine which type of family climate was a significant moderator of the relationship between ADHD symptoms and perceived family support, ADHD symptoms and depression, and perceived family support and depression. We found that only the family climate perceived as helpful was a moderator of the relationship between perceived family support and depression (Fig. 2). Therefore, we used Hayes's Model 14, a moderated mediation analysis that simultaneously tests how a relationship between an antecedent variable $(\mathrm{X})$ and an outcome variable $(\mathrm{Y})$ depends on the level of the moderator. In this case, we tested a moderated mediation model in which depression was regressed on ADHD symptoms through perceived family support.

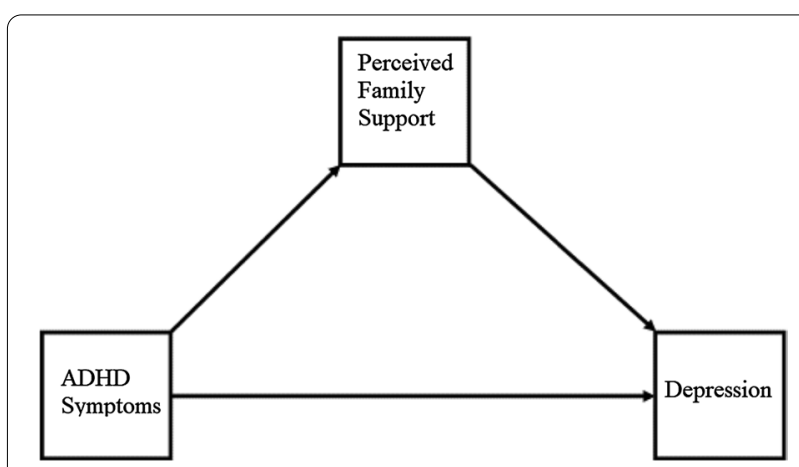

Fig. 1 Mediation model 


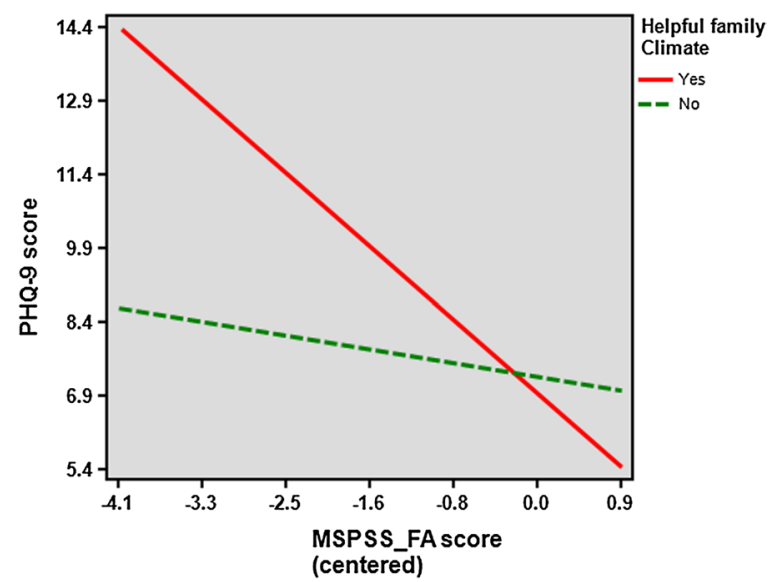

Fig. 2 Relationship between PHQ-9 and MSPSS (family) scores for family climate perceived as helpful (yes) or as not helpful (no). MSPSS_FA Multidimensional Scale of Perceived Social support (family subscale), PHQ-9nine-Item Patient Health Questionnaire

Model 14 further specifies that the effect of the hypothesized mediating or antecedent variable (perceived family support) on the outcome or consequent variable (depression) is conditional on the moderating variable (helpful family climate). Significant interaction (perceived family support $\times$ helpful family climate) was examined by visualizing predicted values of depression-centered scores with the presence or absence of helpful family climate [53]. We used resampling or bootstrapping and the product of coefficients as suggested by Preacher and Hayes when conducting mediation and moderation analyses $[53,54]$

We used PROCESS v3.4, an add-on statistical analysis for SPSS created by Hayes [55], for all mediation and moderation analyses. For interpretation, PROCESS provides standard errors, $p$-values, confidence intervals for the direct effect coefficients, and bootstrap confidence intervals for conditional indirect effects and for conditional indirect effects pairwise contrasts. Confidence intervals that do not straddle zero are indicative of statistical significance. For all the analyses, the level of significance was set at $p<0.05$. All statistical analyses were performed using the program IBM SPSS 22.0.

\section{Results}

As shown in Table 1, 62.9\% of the participants were female, with an age range of 17 to 21 years. None reported any mental illness or being under any medication. Both parents had an average of 15 years of education. Slightly over one half of the participants were firstborn. The median number of siblings was 2 (range $=1$ to 6 ). Most participants described the family they grew up in as enjoyable (83.9\%), helpful (85.5\%), and warm (83.9\%).
Table 1 Sociodemographic characteristics of the participants

\begin{tabular}{ll}
\hline Variable & $\mathbf{n}(\%)$ or mean \pm SD \\
\hline Male & $46(37.1)$ \\
Age (years) & $18.78 \pm 0.74$ \\
Father's years of education & $14.98 \pm 5.6$ \\
Father's mental illness & $1(0.8)$ \\
Mother's years of education & $14.71 \pm 5.7$ \\
Mother's mental illness & 0 \\
Single child & $18(14.5)$ \\
Firstborn & $65(52.4)$ \\
Last born & $46(37.4)$ \\
Number of siblings & $2.1 \pm 0.79$ \\
Family climate & \\
Quiet-lonesome & $5(4)$ \\
Enjoyable & $104(83.9)$ \\
Chaotic & $6(4.8)$ \\
Ignoring/detached & $1(0.8)$ \\
Helpful & $106(85.5)$ \\
Intrusive & $8(6.5)$ \\
Distant & $0(0)$ \\
Warm-relaxing & $104(83.9)$ \\
Uncomfortable/tense & $8(6.5)$ \\
\hline
\end{tabular}

ADHD symptoms, PHQ-9 scores, and MSPSS_FA scores were significantly related to each other, while no significant correlations between family climate and ADHD symptoms were found (Table 2). As expected, positive climate factors-enjoyable, helpful, and warmpositively correlated with MSPSS_FA scores, but negatively correlated with the PHQ-9 scores, while negative family climate factors positively correlated with the PHQ-9, but negatively correlated with the MSPSS_FA.

\section{Mediation model}

The mediation model showed that both ADHD symptoms and perceived family support had a significant effect on depression. Perceived family support reduced the effect of ADHD symptoms from $0.07 \quad(t=3.022$, $p=0.003)$ to $0.058(t=2.141, p=0.0343)$. ADHD symptoms appeared to have an indirect, rather than a direct effect, on depression through perceived family support.

Figure 2 shows the relationship between PHQ-9 and MSPSS_FA scores based on the presence or absence of a family climate perceived as helpful. Moderational analysis showed that the slope for the presence of a helpful family climate was $-1.817(95 \% \mathrm{CI}=-2.579,-1.054$; standard error of slope $=0.38$; degrees of freedom $=111$; $t=-4.721, p<0.0001)$; while the absence of a helpful family climate was $-0.336(95 \% \mathrm{CI}=-2.151,1.479$; standard error of the slope $=0.92$; degrees of freedom $=111$; $t=-0.366, \quad p=0.357)$. Therefore, for participants 
Table 2 Correlation matrix between family climate and clinical variables

\begin{tabular}{|c|c|c|c|c|c|c|c|c|c|c|c|c|}
\hline Variables & $M(S D)$ & 1 & 2 & 3 & 4 & 5 & 6 & 7 & 8 & 9 & 10 & 11 \\
\hline Quiet-lonesome & $0(0)$ & 1 & & & & & & & & & & \\
\hline Enjoyable & $1(0)$ & $-.467^{* *}$ & 1 & & & & & & & & & \\
\hline Chaotic & $0(0)$ & -.046 & $-.514^{* *}$ & 1 & & & & & & & & \\
\hline Ignoring/detached & $0(0)$ & -.018 & $-.206^{*}$ & $.400^{* *}$ & 1 & & & & & & & \\
\hline Helpful & $1(0)$ & .084 & $.566^{* *}$ & $-.227^{*}$ & $-.219^{*}$ & 1 & & & & & & \\
\hline Intrusive & $0(0)$ & -.054 & -.063 & $.247^{* *}$ & -.024 & $-.637^{* *}$ & 1 & & & & & \\
\hline Warm-relaxing & $1(0)$ & -.022 & $.523^{* *}$ & -.105 & $-.206^{*}$ & $.628^{* *}$ & -.153 & 1 & & & & \\
\hline Uncomfortable/tense & $0(0)$ & .113 & -.153 & $.247^{* *}$ & $.343^{* *}$ & $-.265^{* *}$ & $.332^{* *}$ & $-.599^{* *}$ & 1 & & & \\
\hline ADHD symptoms & $10.1(3.5)$ & -.122 & -.072 & .137 & .013 & -.164 & .145 & .029 & .016 & 1 & & \\
\hline MSPSS_FA score & $6.1(1.0)$ & -.096 & $.320^{* *}$ & $-.287^{* *}$ & -.029 & $.270^{* *}$ & $-.224^{*}$ & $.284^{* *}$ & $-.299^{* *}$ & $-.264^{* *}$ & 1 & \\
\hline PHQ-9 score & $7.2(3.9)$ & .128 & $-.309^{* *}$ & .086 & .089 & $-.218^{*}$ & -.005 & $-.235^{* *}$ & .106 & $.268^{* *}$ & $-.368^{* *}$ & 1 \\
\hline
\end{tabular}

$\mathrm{M}(\mathrm{SD})=$ mean (standard deviation); from Quiet-lonesome to Uncomfortable/tense variables, the values are median (interquartile range) ${ }^{*} p<0.05 ;{ }^{* *} p<0.01$

MSPSS_FA Multidimensional Scale of Perceived Social support (family subscale), PHQ-9Nine-Item Patient Health Questionnaire, Distant family climate was omitted from analysis

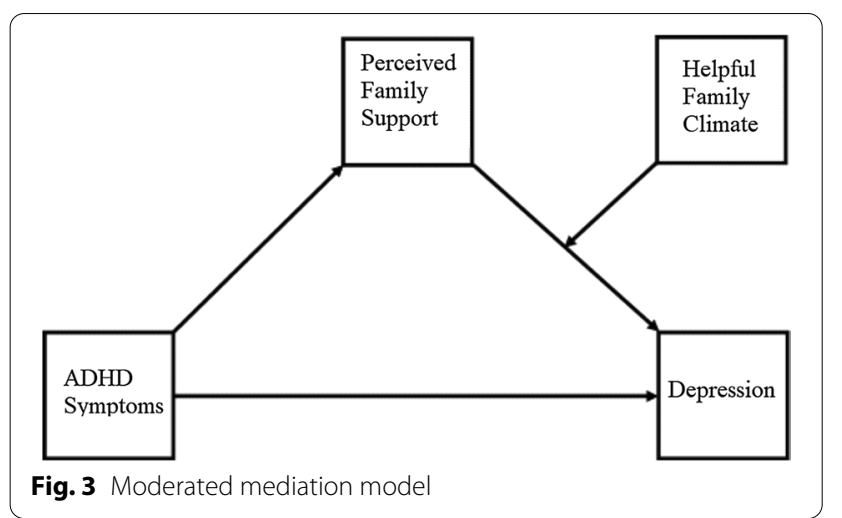

perceiving their family climate as being helpful, the correlation between perceived family support and depression was significantly negative (Fig. 3).

Moderation analysis showed that perceived family support yielded significantly different effects on depression for the group that perceived a helpful family climate (effect $=0.0349, \quad$ BootSE $=0.0191, \quad$ BootLLCI $=0.0036$, and BootULCI $=0.0786$ ).

The MSPSS_FA significantly mediated the relationship between ADHD symptoms and the PHQ-9 $(t=-0.3 .716$, $p=0.0003$; Table 3), while a significant moderation effect of helpful family climate on decreased depression was

Table 3 The results of the mediation model and moderated mediation model

\begin{tabular}{|c|c|c|c|c|c|c|}
\hline PHQ-9 & Coefficient & SE & $t$ & $p$ value & LLCl & ULCI \\
\hline \multicolumn{7}{|l|}{ Mediation model } \\
\hline ADHD symptoms & 0.058 & 0.027 & 2.141 & 0.0343 & 0.004 & 0.112 \\
\hline MSPSS_FA & -1.241 & 0.334 & -3.716 & 0.0003 & -1.901 & -0.58 \\
\hline$R^{2}$ & 0.1671 & & & & & \\
\hline Indirect effect & 0.084 & 0.043 & & & 0.012 & 0.177 \\
\hline \multicolumn{7}{|l|}{ Moderated mediation model } \\
\hline ADHD symptom & 0.047 & 0.027 & 1.727 & 0.0867 & -0.007 & 0.100 \\
\hline MSPSS_FA (M) & -0.096 & 0.594 & -0.161 & 0.8726 & -1.272 & 1.081 \\
\hline Helpful family climate (W) & 7.432 & 4.160 & 1.787 & 0.0766 & -0.806 & 15.669 \\
\hline$M^{*} W$ & -1.5331 & 0.7201 & -2.129 & 0.0353 & -2.959 & -0.107 \\
\hline$R^{2}$ & 0.2084 & & & & & \\
\hline Index of moderated mediation & 0.033 & 0.026 & & & -0.005 & 0.094 \\
\hline
\end{tabular}


also observed $(t=-2.129, p=0.035)$. Compared with the mediation model, the moderated mediation model increased $R^{2}$ from 16.7 to $20.8 \%$. A conditional process model produced the effect of 0.033 for the index of moderated mediation, with a $95 \%$ bootstrap confidence interval between -0.0053 and 0.0944 . As this confidence interval straddles zero, this provided evidence that the indirect effect of ADHD symptoms concerning depression through perceived family support was not moderated by helpful family climate. In other words, as the confidence interval straddled zero, we could not claim definitively that the indirect effect varied linearly as a function of helpful family climate; hence, no moderation of mediation was indicated.

\section{Discussion}

This study aimed to examine the extent to which perceived family support and family climate contributed to decreased depression among medical students. Despite the increase (from 17 to $21 \%$ ) in the variance in depression explained by adding the variables perceived family support and helpful family climate, the indirect effect of ADHD symptoms through perceived family support was not significantly linearly contingent on helpful family climate. In the mediation model, depression was explicitly influenced by the direct effect of perceived family support and the mediating effect of ADHD symptoms. The impact of helpful family climate was not large, despite having a moderating effect on perceived support for depression. The main reason for the nonsignificance may be attributed to the fact that the sample size was not sufficiently large to capture small differences. Another possible reason may be that the family climate data collected focused on the respondent's experience rather than the current family atmosphere, which should have a greater interaction effect with the current feeling of family support. This finding was in line with that of a related study [30].

Perceived family support intuitively positively correlates with positive family climate, i.e., enjoyable, helpful, and warm, but negatively correlates with negative family climate, i.e., chaotic and intrusive. However, our analysis showed that only helpful family climate was a significant moderator in the moderation model. These findings are supported by Wüstner et al. in that no associations were observed initially between family climate and ADHD but at a later time [45]. However, the main emphasis of the two studies differed; this study focused on depression, while Wüstner et al. focused on ADHD symptoms. Moreover, the current study found an association between perceived family support and ADHD symptoms and depression, whereas Wüstner et al. found that social support reduced the association between strong parental mental health problems and strong ADHD symptoms. Further study is worth pursuing to test the longitudinal effect of perceived family (or social) support on the relationship between ADHD symptoms and depression.

Notably, regarding family climate, related studies have suggested that negative family relationships could increase the incidence of ADHD symptoms [56], and that ADHD symptoms had an impact on family climate. This constitutes a vicious cycle [33]. Oddly enough, the present study did not find a relationship between either positive or negative family climate and ADHD symptoms; this could possibly have been because the questionnaire was insufficient to capture the significant relationships found in related studies [30].

\section{Strengths and limitations}

To the best of our knowledge, this study is one of the first concerning the importance of perceived family support and helpful family climate on depression in adult ADHD. Further investigations based on these results are recommended. Given that ADHD is highly prevalent and causes significant impairments in almost all areas of life, our findings have important implications for prevention and clinical practice. In addition to family-based interventions, future prevention and early intervention programs should focus on the availability of good social support and enhancing social skills, particularly among children of mentally ill parents, to reduce risks and prevent the onset of ADHD symptoms.

This study encountered several limitations. First, the sample size was small and the participants were all first year medical students, which cannot represent the general medical student body. We used self-reported data to assess ADHD symptoms without interview confirmation, yielding a disproportionately high prevalence. We did not evaluate conditions highly comorbid with ADHD, including bipolar disorder, anxiety disorder, and personality disorder. Future studies are required to further understand ADHD symptoms and mental health-related conditions among medicals students. In addition, this study lacked information about parental ADHD, which may be related to negative family climate.

\section{Conclusion}

The findings of the study revealed that poor family support might be one risk of developing depression in the context of ADHD symptoms. Further study on providing intervention concerning family support among those with ADHD symptoms should be warranted. In addition, a study on helpful family climate using a larger sample size, as well as in other populations, and in a longitudinal fashion for a more robust conclusion is encouraged. 


\section{Abbreviations}

ADHD: Attention deficit hyperactivity disorder; ASRS: Adult ADHD Self-Report Scale; MSPSS-FA: Multidimensional Scale of Perceived Social Support-Family; PHQ-9: 9-Item Patient Health Questionnaire.

\section{Acknowledgements}

This research project, a part of the project 'SAMME', was supported by a research grant from the Faculty of Medicine, Chiang Mai University in the Kingdom of Thailand.

\section{Authors' contributions}

PP, NW, TW, CB conceived the research idea and designed the study. CB, SS, SC, and PK collected data. NW, TW, PP, and CB analyzed data. PP, NW, TW, CB, SS, SC, and PK drafted the manuscript. All revised and approved the manuscript.

\section{Funding}

This study was funded by the Faculty of Medicine, Chiang Mai University. The funder had no role in study design, data collection and analysis, decision to publish, or preparation of the manuscript.

\section{Availability of data and materials}

The datasets used and/or analyzed during the current study are available from the corresponding author on reasonable request.

\section{Declarations}

\section{Ethics approval and consent to participate}

This study was approved by the research ethics committee of the Faculty of Medicine, Chiang Mai University. All patients provided written informed consent to the study,

\section{Consent for publication}

Consent for publication is not applicable.

\section{Competing interests}

Tinakon Wongpakaran is an editorial member of BMC Psychiatry. All the authors declare that they have no competing interests.

\section{Author details}

${ }^{1}$ Faculty of Medicine, Chiang Mai University, Chiang Mai, Thailand. ${ }^{2}$ Department of Psychiatry, Faculty of Medicine, Chiang Mai University, 110 Intawaroros Rd., T. Sriphum, A. Muang, Chiang Mai 50200, Thailand.

Received: 18 November 2020 Accepted: 21 June 2021

Published online: 28 July 2021

\section{References}

1. Nelson JM, Liebel SW. Anxiety and depression among college students with attention-deficit/hyperactivity disorder (ADHD): cross-informant, sex, and subtype differences. J Am Coll Health. 2018;66(2):123-32.

2. Thorell LB, Holst Y, Sjöwall D. Quality of life in older adults with ADHD: links to ADHD symptom levels and executive functioning deficits. Nord J Psychiatry. 2019;73(7):409-16.

3. Sibley MH, Graziano PA, Ortiz M, Rodriguez L, Coxe S. Academic impairment among high school students with ADHD: The role of motivation and goal-directed executive functions. J Sch Psychol. 2019;77:67-76.

4. Bjerrum MB, Pedersen PU, Larsen P. Living with symptoms of attention deficit hyperactivity disorder in adulthood: a systematic review of qualitative evidence. JBI Database Syst Rev Implement Rep. 2017;15(4):1080-153.

5. Kessler RC, Adler L, Ames M, Barkley RA, Birnbaum H, Greenberg P, Johnston JA, Spencer T, Ustün TB. The prevalence and effects of adult attention deficit/hyperactivity disorder on work performance in a nationally representative sample of workers. J Occup Environ Med. 2005;47(6):565-72.

6. Chung YR, Hong JW, Kim BB, Kim JS, Noh IS, Wee JH, Kim NH, Bae SM, Lim MH. ADHD, suicidal ideation, depression, anxiety, self-esteem, and alcohol problem in Korean juvenile delinquency. Medicine (Baltimore). 2020;99(11):e19423.

7. Arsandaux J, Orri M, Tournier M, Gbessemehlan A, Coté S, Salamon R, Tzourio C, Galéra C. Pathways from ADHD symptoms to suicidal ideation during college years: a longitudinal study on the i-Share Cohort. J Atten Disord. 2020;1087054720915246. https://doi.org/10.1177/10870 54720915246.

8. Sayal K. Attention deficit hyperactivity disorder is associated with poorer academic performance. Evid Based Ment Health. 2008;11(2):41.

9. Tuttle JP, Scheurich NE, Ranseen J. Prevalence of ADHD diagnosis and nonmedical prescription stimulant use in medical students. Acad Psychiatry. 2010;34(3):220-3.

10. Biederman J, Faraone SV. The effects of attention-deficit/hyperactivity disorder on employment and household income. MedGenMed. 2006;8(3):12.

11. Fredriksen M, Dahl AA, Martinsen EW, Klungsoyr O, Faraone SV, Peleikis DE. Childhood and persistent ADHD symptoms associated with educational failure and long-term occupational disability in adult ADHD. Atten Defic Hyperact Disord. 2014;6(2):87-99.

12. Vingilis E, Erickson PG, Toplak ME, Kolla NJ, Mann RE, Seeley J, van der Maas M, Daigle DS. Attention deficit hyperactivity disorder symptoms, comorbidities, substance use, and social outcomes among men and women in a Canadian sample. Biomed Res Int. 2015;201:982072.

13. Mclntyre RS, Kennedy SH, Soczynska JK, Nguyen HT, Bilkey TS, Woldeyohannes HO, Nathanson JA, Joshi S, Cheng JS, Benson KM et al. Attention-deficit/hyperactivity disorder in adults with bipolar disorder or major depressive disorder: results from the international mood disorders collaborative project. Prim Care Companion J Clin Psychiatry. 2010;12(3):PCC.09m00861. https://doi.org/10.4088/PCC.09m00861 gry.

14. Pan PY, Yeh CB. Impact of depressive/anxiety symptoms on the quality of life of adolescents with ADHD: a community-based 1-year prospective follow-up study. Eur Child Adolesc Psychiatry. 2017;26(6):659-67.

15. Pehlivanidis A, Papanikolaou K, Mantas V, Kalantzi E, Korobili K, Xenaki LA, Vassiliou G, Papageorgiou C. Lifetime co-occurring psychiatric disorders in newly diagnosed adults with attention deficit hyperactivity disorder (ADHD) or/and autism spectrum disorder (ASD). BMC Psychiatry. 2020;20(1):423.

16. Kessler RC, Adler L, Barkley R, Biederman J, Conners CK, Demler O, Faraone SV, Greenhill LL, Howes MJ, Secnik K, et al. The prevalence and correlates of adult ADHD in the United States: results from the National Comorbidity Survey Replication. Am J Psychiatry. 2006;163(4):716-23.

17. Torgersen T, Gjervan B, Rasmussen K. ADHD in adults: a study of clinical characteristics, impairment and comorbidity. Nord J Psychiatry. 2006;60(1):38-43.

18. Franke B, Michelini G, Asherson P, Banaschewski T, Bilbow A, Buitelaar JK, Cormand B, Faraone SV, Ginsberg Y, Haavik J, et al. Live fast, die young? a review on the developmental trajectories of ADHD across the lifespan. Eur Neuropsychopharmacol. 2018;28(10):1059-88.

19. Polyzoi M, Ahnemark E, Medin E, Ginsberg Y. Estimated prevalence and incidence of diagnosed ADHD and health care utilization in adults in Sweden - a longitudinal population-based register study. Neuropsychiatr Dis Treat. 2018;14:1149-61.

20. Kwak YS, Jung YE, Kim MD. Prevalence and correlates of attentiondeficit hyperactivity disorder symptoms in Korean college students. Neuropsychiatr Dis Treat. 2015;11:797-802.

21. Shen Y, Chan BSM, Liu J, Meng F, Yang T, He Y, Lu J, Luo X, Zhang XY. Estimated prevalence and associated risk factors of attention deficit hyperactivity disorder (ADHD) among medical college students in a Chinese population. J Affect Disord. 2018;241:291-6.

22. Tsai F-J, Tseng W-L, Yang L-K. Gau SS-F: psychiatric comorbid patterns in adults with attention-deficit hyperactivity disorder: treatment effect and subtypes. PLoS ONE. 2019;14(2):e0211873-e0211873.

23. BaP-LLaCWaBA S-Z. Adjustment, social skills, and self-esteem in college students with symptoms of ADHD. J Atten Disord. 2005:8(3):109-20.

24. Kita $Y$, Inoue $Y$. The direct/indirect association of ADHD/ODD symptoms with self-esteem, self-perception, and depression in early adolescents. Front Psych. 2017;8:137-137.

25. Alvarez-Fernandez S, Brown HR, Zhao Y, Raithel JA, Bishop SL, Kern SB, Lord C, Petkova E, Di Martino A. Perceived social support in adults with autism spectrum disorder and attention-deficit/hyperactivity disorder. Autism Res. 2017;10(5):866-77. 
26. Mastoras SM, Saklofske DH, Schwean VL, Climie EA. Social support in children with ADHD: an exploration of resilience. J Atten Disord. 2018;22(8):712-23.

27. Margalit M. Family climate. In: Margalit M, editor. Effective technology integration for disabled children: the family perspective. New York: Springer; 1990. p. 71-82.

28. Brinksma DM, Dietrich A, de Bildt A, Buitelaar JK, van den Hoofdakker BJ, Hoekstra PJ, Hartman CA. ADHD symptoms across adolescence: the role of the family and school climate and the DRD4 and 5-HTTLPR genotype. Eur Child Adolesc Psychiatry. 2020;29(8):1049-61. https://doi.org/10.1007/ s00787-019-01424-3.

29. Amato PR. Explaining the intergenerational transmission of divorce. J Marriage Fam. 1996;58(3):628-40.

30. Uçar HN, Eray \$̧, Vural AP, Kocael Ö: Perceived family climate and selfesteem in adolescents with ADHD: a study with a control group. J Atten Disorders. 2020;24(8):1132-40. https://doi.org/10.1177/1087054717 696772.

31. Sellers R, Harold GT, Smith AF, Neiderhiser JM, Reiss D, Shaw D, Natsuaki MN, Thapar A, Leve LD. Disentangling nature from nurture in examining the interplay between parent-child relationships, ADHD, and early academic attainment. Psychol Med. 2019;51:1-8.

32. Palladino VS, McNeill R, Reif A, Kittel-Schneider S. Genetic risk factors and gene-environment interactions in adult and childhood attention-deficit/ hyperactivity disorder. Psychiatr Genet. 2019;29(3):63-78.

33. Kousgaard SJ, Boldsen SK, Mohr-Jensen C, Lauritsen MB. The effect of having a child with ADHD or ASD on family separation. Soc Psychiatry Psychiatr Epidemiol. 2018;53(12):1391-9.

34. Crea TM, Chan K, Barth RP. Family environment and attention-deficit/ hyperactivity disorder in adopted children: associations with family cohesion and adaptability. Child Care Health Dev. 2014;40(6):853-62.

35. Ackerman RA, Kashy DA, Donnellan MB, Neppl T, Lorenz FO, Conger RD. The interpersonal legacy of a positive family climate in adolescence. Psychol Sci. 2013;24(3):243-50.

36. Huang $Y, X u H, A u$ W, Xu C, Wu K. Involvement of family environmental, behavioral, and social functional factors in children with attention-deficit/ hyperactivity disorder. Psychol Res Behav Manag. 2018;11:447-57.

37. Yin P, Hou X, Qin Q, Deng W, Hu H, Luo Q, Du L, Qiu H, Qiu T, Fu Y, et al. Genetic and environmental influences on the mental health of children: a twin study. J Psychosoc Nurs Ment Health Serv. 2016;54(8):29-34.

38. Eray S, Vural AP, Sigirli D. School going adolescents' perception of family climate and mental problems: results from Kocaeli, Turkey. J Pak Med Assoc. 2017:67(5):706-10.

39. Luebbe AM, Bell DJ. Positive and negative family emotional climate differentially predict youth anxiety and depression via distinct affective pathways. J Abnorm Child Psychol. 2014;42(6):897-911.

40. Yu Y, Yang X, Yang Y, Chen L, Qiu X, Qiao Z, Zhou J, Pan H, Ban B, Zhu $X$, et al. The role of family environment in depressive symptoms among university students: a large sample survey in China. PLOS ONE. 2015;10(12):e0143612-e0143612.

41. Roy A, Hartman CA, Veenstra R, Oldehinkel AJ. Peer dislike and victimisation in pathways from ADHD symptoms to depression. Eur Child Adolesc Psychiatry. 2015;24(8):887-95.

42. Humphreys KL, Katz SJ, Lee SS, Hammen C, Brennan PA, Najman JM. The association of ADHD and depression: mediation by peer problems and parent-child difficulties in two complementary samples. J Abnorm Psychol. 2013;122(3):854-67.

43. Stickley A, Koyanagi A, Takahashi H, Ruchkin V, Inoue Y, Yazawa A, Kamio Y. Attention-deficit/hyperactivity disorder symptoms and happiness among adults in the general population. Psychiatry Res. 2018;265:317-23.

44. Gordon CT, Hinshaw SP. Parenting stress as a mediator between childhood ADHD and early adult female outcomes. J Clin Child Adolesc Psychol. 2017;46(4):588-99.

45. Wüstner A, Otto C, Schlack R, Hölling H, Klasen F, Ravens-Sieberer U. Risk and protective factors for the development of ADHD symptoms in children and adolescents: results of the longitudinal BELLA study. PLOS ONE. 2019;14(3):e0214412.

46. Kessler RC, Adler L, Ames M, Demler O, Faraone S, Hiripi E, Howes MJ, Jin R, Secnik K, Spencer T, et al. The World Health Organization Adult ADHD Self-Report Scale (ASRS): a short screening scale for use in the general population. Psychol Med. 2005;35(2):245-56.

47. Bussaratid S, Atsariyasing W, Wannarit K, Pukrittayakami P, Hosiri T, Wiwatwararom N, Pornnoppadol C. Reliability and validity study of adult ADHD Self-Report Scale (ASRS) screener v1.1 Thai version. J Psychiatr Assoc Thailand. 2016;61(2):145-54.

48. Kiatrungrit K, Putthisri S, Hongsanguansri S, Wisajan P, Jullagate S. Validity and reliability of adult ADHD Self-Report Scale Thai version (ASRS-V1.1 TH). Shanghai Arch Psychiatry. 2017;29(4):218-27.

49. Kroenke K, Spitzer RL, Williams JB. The PHQ-9: validity of a brief depression severity measure. J Gen Intern Med. 2001;16(9):606-13.

50. Lotrakul M, Sumrithe S, Saipanish R. Reliability and validity of the Thai version of the PHQ-9. BMC Psychiatry. 2008;8:46.

51. Zimet GD, Powell SS, Farley GK, Werkman S, Berkoff KA. Psychometric characteristics of the Multidimensional Scale of Perceived Social Support. J Pers Assess. 1990;55(3-4):610-7.

52. Wongpakaran $\mathrm{N}$, Wongpakaran $\mathrm{T}$. A revised Thai multi-dimensional scale of perceived social support. Span J Psychol. 2012;15(3):1503-9.

53. Hayes AF. Introduction to mediation, moderation, and conditional process analysis: a regression-based approach. 2nd ed. New York: Guilford Press; 2018.

54. Preacher KJ, Hayes AF. Asymptotic and resampling strategies for assessing and comparing indirect effects in multiple mediator models. Behav Res Methods. 2008:40(3):879-91.

55. Hayes AF. Introduction to mediation, moderation, and conditional process analysis: A regression-based approach. New York: Guilford Press; 2013.

56. Huhdanpää H, Morales-Muñoz I, Aronen ET, Pölkki P, Saarenpää-Heikkilä $\mathrm{O}$, Kylliäinen A, Paavonen EJ. Prenatal and postnatal predictive factors for children's inattentive and hyperactive symptoms at 5 years of age: the role of early family-related factors. Child Psychiatry Hum Dev. 2020. https://doi.org/10.1007/s10578-020-01057-7.

\section{Publisher's Note}

Springer Nature remains neutral with regard to jurisdictional claims in published maps and institutional affiliations.

Ready to submit your research? Choose BMC and benefit from

- fast, convenient online submission

- thorough peer review by experienced researchers in your field

- rapid publication on acceptance

- support for research data, including large and complex data types

- gold Open Access which fosters wider collaboration and increased citations

- maximum visibility for your research: over 100M website views per year

At $\mathrm{BMC}$, research is always in progress.

Learn more biomedcentral.com/submissions 